CARPATHIAN JOURNAL OF FOOD SCIENCE AND TECHNOLOGY

journal home page:http://chimie-biologie.ubm.ro/carpathian_journal/index.html

\title{
BIOLOGICALLY ACTIVE COMPLEX FOR MULTIFACTORIAL SUPPORT OF THE CENTRAL NERVOUS SYSTEM: NEW COMPOSITION, EFFICACY
}

\author{
Boisjoni Tokhiriyon $^{1 凶}$, Valery Mikhailovich Poznyakovsky $^{1}$, Svetlana Sergeevna Andrievskikh $^{1}$ \\ ${ }^{1}$ Ural State University of Economics, 620219, Yekaterinburg, March 8 street, 62, Russian Federation \\ \tohiriyoni@gmail.com \\ https://doi.org/10.34302/crpifst/2020.12.1.5 \\ Article history: \\ Received: \\ 23 November 2019 \\ Accepted: \\ 22 January 2020 \\ Keywords: \\ Biologically active food \\ supplement; \\ Supplement formula; \\ Central nervous system; \\ Functional properties; \\ Efficacy.

\begin{abstract}
A new tablet form of biologically active food supplement for the multifactorial support of the central nervous system has been developed. It is named Supplement The supplement production technology prevents ingredients oxidative processes due to insignificant moisture content and exclusion of the active oxygen exposure. The biologically active complex facilitates memory retention and information retrieval, accelerates thinking process, and boosts the level of the overall energy potential by improving the central nervous system activity. A balanced combination of active substances (schisandra chinensis, ginkgo biloba) and sedative herbal components (valeriana, motherwort) allows achieving "fine tuning" effect when the above mentioned components act in the best way. These ingredients improve nerve tissue trophism, brain vessels tone, venous outflow and prevent hypertension. Essential and dispensable amino acids in the complex, such as tryptophan, glycine, tyrosine and glutamic acid, make it possible to control neuromediators synthesis and the molecular basis of memory, optimize carbohydrate-fat metabolism, accelerate the process of impulse transmission along the nerve fiber, while avoiding overexcitement. Most of the amino acids in the food supplement have antidepressant effect. Paraaminobenzoic acid reduces mental and physical fatigue and prevents hypoxia in the central nervous system. Another complex ingredient, Inositol, is one of the main nutrient components of the nerve tissue which contributes to its structure restoration. Group B vitamins help replenish energy and ensure its maximum use by the nerve tissue. The paper provides regulated indicators of the nutritional value of a specialized medical product that determine its functional properties. Efficacy was confirmed by clinical trials on a group of patients with angioneurosis. The authors demonstrated hygienic security of the developed product, its shelf life and storage conditions. They also conducted its production testing.
\end{abstract}

\section{Introduction}

Brain diseases have always been a topical problem due to their high occurrence and serious health consequences [Avstrievskikh et al., 2005; Kondratiev et al., 2015]. The initial period of pathologies under consideration are characterized by emotional instability, irritation, increased fatigability [Lebedeva et al., 2010; Osipova et al., 2012].
Negative influence of different environmental factors, including increased influence of free radicals, lead to even more serious brain [Fenech et al., 2011; Lund al., 2011; Witte and Byrom, 2014]. Headaches, dizziness, sleep disorders become constant and thinking possesses slow down. Absence of timely preventive measures may result in a stroke and other diseases of nervous and cardio-vascular 
systems even at a young age [Chelnakova et al., 2015; Mirmiran et al., 2014; Stovner et al., 2007]. A proper diet, including nutrition supplement intake, plays an important part in solving these problems [Poznyakovsky et al., 2017; Bokeria, 2012]. This is the fastest and most effective way of dealing with the problems, proven by numerous research of Russian and foreign scientists [Fenech et al., 2011; Fulgoni et al., 2011; Gemming et al., 2013; Mozaffarian and Ludwig, 2010; Shukla and Manju Lata Mishra, 2018].

\section{Materials and methods}

The new formula of food supplement "Supplement" includes the following ingredients (mg per tablet): schisandra chinensis extract - $25 \mathrm{mg}$, valeriana officinalis extract $10 \mathrm{mg}$, gingko biloba extract - $20 \mathrm{mg}$, motherwort extract - $25 \mathrm{mg}$, 5hydroxytryptophan $-75 \mathrm{mg}$, glycine $-75 \mathrm{mg}$, glutamic acid - $75 \mathrm{mg}$, para-aminobenzoic acid (tyrosine) - $150 \mathrm{mg}$, inositol - $75 \mathrm{mg}$, thiamine mononitrate - $0.85 \mathrm{mg}$, pyridoxine hydrochloride (vitamin B6) - $1 \mathrm{mg}$, nicotineamide - $10 \mathrm{mg}$, calcium panthothenate (vitamin B5) - $2.5 \mathrm{mg}$, sifrol-5 - $100 \mathrm{mg}$, tocopherol acetate (vitamin E) $-5 \mathrm{mg}, \mathrm{B}$ carotene $-1.75 \mathrm{mg}$, vitamin $\mathrm{C}-12.5 \mathrm{mg}$, hesperedin $-20 \mathrm{mg}$, dihydroquercetin $-5 \mathrm{mg}$, superoxide dismutase - $100 \mathrm{mg}$, coenzyme Q10 $-1.25 \mathrm{mg}$, hibiscus extract $-11.5 \mathrm{mg}$.

To determine the functional properties of the food supplement it is advisable to characterize its components and their acting substances. [Gerasimenko et al., 2016; Krishnasree et al., 2018; Priya Sugandhi,2018; Vekovtsev et al., 2017; Lafaille, 2012]. Ginkgo biloba (extract) the activity is determined by its flavonoids. Ginkgo biloba improves blood circulation, increases oxygen supply to the heart, brain and other organs, has an antioxidant effect, reduces blood pressure, and inhibits thrombotic risks. Valeriana officinalis acts as a sedative for people with central nervous system functional disorders, neuroses, hysteria, agitation caused by psychic trauma, insomnia, migraine; with cardio neuroses, impaired chronic coronary circulation, and heart pains; with high blood pressure, tachycardia caused by neurotic condition. It also helps reduce angioneurosis. Motherwort also acts as a sedative for nervous tension, hypertension, neuralgia, heart weakness, improves sleep and overall health. Its properties are similar to those of valeriana officinalis. 5-hydroxytryptophan, tryptophan amino acid, is a serotonin precursor. Serotonin may be called "neurotransmitter of happiness", satisfaction and tranquility. That is why 5hydroxytryptophan, which helps serotonin production, is the best natural remedy for depression and anxiety. Its effect is as strong as that of synthetic antidepressants. Glycine has a sedative, mild tranquilizing and weak antidepressant effect, reduces feelings of anxiety, fear, and psycho-emotional stress. It has some nootropic properties, improves memory and associative processes. Inositol is a vitaminlike substance, more precisely, 6-atom alcohol. It possesses membrane-protective, antiatherosclerotic, nootropic, antidepressant and sedative properties, improves sleep and metabolism and restores nerve tissue structure. Inositol improves neural signals transmission. It is effectively used in treating diabetic neuropathy (considering its effect on metabolism in general) and diseases characterized by neural hyposensitivity. It is absolutely necessary for spinal cord cells development and functioning. Glutamic acid makes metabolic processes better, promotes oxidative processes and neutralizes protein metabolism byproducts as it binds to ammonia and forms glutamine, thus promoting neutralization and elimination of ammonia from the body, as well as increases the body resistance to hypoxia. This process is especially important in the brain as its tissue is particularly sensitive to ammonia concentration increase. Glutamic acid promotes acetylcholine and ATP synthesis and potassium ions transfer. Tyrosine is a dispensable amino acid which is formed in the body from the essential amino acid, phenylalanine. Tyrosine improves one's mood. Its deficiency leads to brain norepinephrine deficiency, which, in turn, can result in 
depression. PABA (p-aminobenzoic acid) is one of folic acid main components, which promotes pantothenic acid assimilation. Deficiency of PABC can be followed by depression, weakness, irritability, nervousness, and gastrointestinal disorders. PABC promotes the restoration of gray hair, if it is caused by stress.

A balanced combination of active substances (schisandra chinensis, ginkgo biloba) and sedative herbal components (valeriana, motherwort) allows achieving "fine tuning" effect when the above mentioned components act in the best way. These ingredients improve nerve tissue trophism, brain vessels tone, venous outflow and prevent hypertension. Essential and dispensable amino acids in the complex, such as tryptophan, glycine, tyrosine and glutamic acid, make it possible to control neuromediators synthesis and the molecular basis of memory, optimize carbohydrate-fat metabolism, accelerate the process of impulse transmission along the nerve fiber, while avoiding overexcitement. Most of the amino acids in the food supplement have antidepressant effect. Paraaminobenzoic acid reduces mental and physical fatigue and prevents hypoxia in the central nervous system. Another complex ingredient, Inositol, is one of the main nutrient components of the nerve tissue which contributes to its structure restoration. Group B vitamins help replenish energy and ensure its maximum use by the nerve tissue.

The production technology of the suplement tablet form ensures insignificant moisture content and zero active aeration, which prevents destructive oxidative processes of biologically active substances and their active principles.

Comprehensive research has been done to study the supplement properties. The trial results made it possible to determine the regulated (standardized) indicators of quality (table 1), safety (table 2) and nutritional value (table 3), which characterize the supplement functional properties.

Table 1. Organoleptic, physicochemical characteristics and nutritional values of food supplement Supplement.

\begin{tabular}{|l|c|}
\hline \multicolumn{1}{|c|}{ Characteristic } & Description \\
\hline Appearance & Organoleptic characteristics \\
\hline Color & Beige, with brown and green pellets \\
\hline \multicolumn{2}{|c|}{ Physicochemical characteristics } \\
\hline Disintegration time & no longer than 30 min \\
\hline Tablet average weight, g & $1,2 \pm 0,12$ \\
\hline Tensile strength, H, not less & 90 \\
\hline Friability strength, \%, not less & 97 \\
\hline
\end{tabular}

Table 2. Safety characteristics.

\begin{tabular}{|l|c|}
\hline \multicolumn{1}{|c|}{ Characteristc } & $\begin{array}{c}\text { Sample content, mg per kg, } \\
\text { no more than }\end{array}$ \\
\hline Toxic elements: & \\
\hline Lead & 5,0 \\
\hline Cadmium & 1,0 \\
\hline Arsenic & 3,0 \\
\hline Mercury & 1,0 \\
\hline Pesticides: & 0,1 \\
\hline Sum of isomers HCCH & Prohibited \\
\hline Heptachlor & 0,1 \\
\hline DDT and sum of its metabolites & \\
\hline
\end{tabular}




\begin{tabular}{|l|c|}
\hline Aldrin & Prohibited \\
\hline Microbiological characteristics: & $5 \cdot 10^{4}$ \\
\hline $\begin{array}{l}\text { Mesophilic aerobic and facultative anaerobic } \\
\text { microorganisms, CFU per gram }\left(\mathbf{c m}^{\mathbf{3}}\right) \text { of } \\
\text { product }\end{array}$ & 0,1 \\
\hline Coliform bacteria & 10,0 \\
\hline $\begin{array}{l}\text { Pathogenic microorganisms, including } \\
\text { Salmonella }\end{array}$ & 1,0 \\
\hline E. coli & 100 \\
\hline Yeasts and molds, CFU per gram & 200 \\
\hline Radionuclides & 100 \\
\hline Cesium-137, Bq/kg & \\
\hline Strontium-90, Bq/kg & \\
\hline
\end{tabular}

Table 3. Nutritional value of food supplement "Supplement".

\begin{tabular}{|l|c|c|}
\hline \multicolumn{1}{|c|}{ Nutritional value, mg per tablet } & mg & $\begin{array}{c}\text { \% of dietary } \\
\text { reference intake }\end{array}$ \\
\hline Coenzyme Q10 & $1.25 \pm 0,125$ & 8 \\
\hline Hesperidin & $20 \pm 2,0$ & 20 \\
\hline Vitamin C (Ascorbic Acid) & $12,5 \pm 0,125$ & 17,8 \\
\hline Vitamin B1 (Thiamine) & $0,85 \pm 0,125$ & 50 \\
\hline Vitamin B6 (Pyridoxine) & $1,0 \pm 0,1$ & 50 \\
\hline Nicotinamid & $10 \pm 1,0$ & 50 \\
\hline Calcium Pantothenate & $2,5 \pm 0,25$ & 50 \\
\hline Vitamin E (Tocopherol) & $5 \pm 0,5$ & 50 \\
\hline B-Carotene & $1,75 \pm 0,175$ & 35 \\
\hline Dihydroquercetin & $5 \pm 0,5$ & 20 \\
\hline Glycine & $75 \pm 7,5$ & - \\
\hline Tyrosine & $50 \pm 15$ & - \\
\hline Glutamic Acid & 65 & - \\
\hline Schizandrin & 0,4 & - \\
\hline Ginkgo Flavone Glycosides & 3,0 & - \\
\hline
\end{tabular}

Sanitary-hygienic and sanitary-toxicological tests results showed all characteristics compliance with technical regulations requirements [Manufacturing formula TC 027, 2012] and allowed to establish terms and conditions of storage - 3 years in a dry, lightproof place, at a temperature of no higher than $25^{\circ} \mathrm{C}$.

"Supplement" efficacy and functional properties were proved by clinical trials. Patients with angioneurosis and cerebrovascular diseases were selected for this trial.

Altogether 105 patients with angioneurosis were observed and tested. They were divided into 3 groups. The first (main) group included 35 patients who took food supplement "Supplement" one tablet a day with a meal. They also took Trental $(50 \mathrm{mg})$ once a day. The period of treatment was 4 weeks. The second (main) group included 35 patients who took "Supplement" once a day with a meal in combination with Trental and food supplement "Gutta Viva" (1 gram a day). Gutta Viva should be dissolved in a glass of water and taken 1 hour before a meal. The period of treatment was 4 weeks. The third (control) group included 35 patients who took only Trental once a day during 4 weeks. Participants were people aged 38-50. The average age was $42.2 \pm 5.3$. Patients were randomly grouped in terms of their gender, age, disease duration and severity. All of them were diagnosed with angioneurosis of moderate to severe degree. All patients complained about general health deterioration, headaches, 
dizziness, worse memory retention and information retrieval, poor attention and concentration. They also showed emotionalvolitional problems. All patients were clinically checked. Their blood and urine were tested, biochemistry blood test analyzed, ECG and EEG studied. All participants were examined by a neurologist who diagnosed most of them with muscle hypotension; half of them with hypertension and all of them with emotionalvolitional sphere disorders. All patients selfassessed their emotional-volitional sphere using Beck Depression Inventory, Tsung depression scale and Sheehan anxiety scale. 30 patients of the first (main) group, 29 patients of the second (main) and 30 patients of the third (control) group were diagnosed with anxiety-depressive disorders. Thus about 30 participants of each group showed mixed anxiety and depression disorders. Assessment by Beck Depression Inventory revealed that 29 patients in each group had depression. Patients felt sad, were not satisfied with their life, disappointed in themselves and needed additional conditions to get down to work. The average level of depression by Tsung scale was 62 - 63 points (average depression level).

All participants showed a high depression level (not more than 80 points) by Sheehan anxiety scale. Anxiety level of more than 30 points is considered abnormal. The aim of the treatment was to achieve less than 20 points score.
Antioxidant effect of food supplement "Supplement" in combination with food supplement "Gutta Viva" was assessed.

Free radical oxidation process is considered a universal mechanism of cell damage. Most patients (95\%) showed a high level of lipid peroxidation antioxidant - malondialdehyde.

"Supplement" intake in combination with food supplement "Guta Viva" is supposed to result in angioneurosis symptoms lessening: improved memory, attention and concentration, reduced emotional-volitional disorders. To achieve this aim it is essential to improve brain nutrition by the supplement ingredients qualitative and quantitative composition.

Research was done by the Therapy Department of the Advanced Studies School of the Siberian State Medical University headed by E.I. Beloborodova, Doctor of Medical Sciences, Professor, Honored Medical Doctor of the Russian Federation.

\section{Results and discussions}

The treatment of patients suffering from angioneurosis resulted in objectively and subjectively positive dynamics of their condition. "Supplement" tolerance was satisfactory; no side effects on internal organs, nervous system and skin were observed (Table 4). Positive effect was also evident when food supplement Supplement was combined with another supplement "Gutta Viva".

Table 4. Dynamics of angioneurosis clinical manifestations in the main and control groups before and after treatment.

\begin{tabular}{|l|c|c|c|}
\hline Clinical manifestations & $\begin{array}{c}\text { First main group } \\
(\mathbf{3 5} \text { patients) }\end{array}$ & $\begin{array}{c}\text { Second main group } \\
\text { (35 patients) }\end{array}$ & $\begin{array}{c}\text { Third control group } \\
\text { (35 patients) }\end{array}$ \\
\hline $\begin{array}{l}\text { Better general condition } \\
\text { and well-being }\end{array}$ & $30(85 \%)$ & $32(90 \%)$ & $20(40 \%)$ \\
\hline Headache abatement & $28(80 \%)$ & $35(100 \%)$ & $25(50 \%)$ \\
\hline $\begin{array}{l}\text { Better memory retention } \\
\text { and information retrieval }\end{array}$ & $30(85 \%)$ & $35(100 \%)$ & $20(40 \%)$ \\
\hline $\begin{array}{l}\text { Better attention and } \\
\text { concentration }\end{array}$ & $28(80 \%)$ & $30(85 \%)$ & $25(50 \%)$ \\
\hline $\begin{array}{l}\text { Reduced emotional- } \\
\text { volitional disorders }\end{array}$ & $25(70 \%)$ & $30(85 \%)$ & $30(60 \%)$ \\
\hline Better muscular tone & $25(70 \%)$ & $32(90 \%)$ & $20(40 \%)$ \\
\hline Lower blood pressure & $12(35 \%)$ & $17(50 \%)$ & $10(20 \%)$ \\
\hline Positive EEG dynamics & $25(70 \%)$ & $30(85 \%)$ & $10(20 \%)$ \\
\hline
\end{tabular}


As can be seen in Table 4, patients with angioneurosis of the first two main groups showed positive dynamics after treatment, especially in the 2nd main group (who took both "Supplement" and "Gutta Viva" supplements). The overwhelming majority (90\%) noted a better general health condition. All participants $(100 \%)$ pointed to abated headaches, $100 \%$ demonstrated better memory retention and information retrieval, $85 \%$ spoke of better attention, concentration and reduced emotionalvolition disorders.

Twenty-five patients $(70 \%)$ in the 1 st main group and the majority of patients $(85 \%)$ in the 2nd main group, showed positive dynamics on EEG. As for the patients from the control group, we can also observe some clinical improvement, but significantly lower than in the main groups. Only $25 \%$ had lower blood pressure, and only $20 \%$ demonstrated positive EEG dynamics, while the main groups' results were 3 times as good.

After 4-week of the supplement Supplement intake in combination with Trental (in the first main group), "Supplement" + Trental + "Gutta Viva"(in the second main group) and only Trental (in the control group) we can observe the decline in the level of malondialdehyde. However, only 17 patients $(50 \%)$ in the first group demonstrated a significant reduction by 1.4 times $(\mathrm{p}<0.05)$, while the majority of the patients in the second main group $(90 \%)$ showed a more significant reduction of 1.9 times $(\mathrm{p}<$ $0.01)$. Only $20 \%$ of patients in the third control group showed the level decline, so we cannot speak of malondialdehyde level normalization (table 5, fig.1).

Table 5. Malondialdehyde level dynamics in patients with angioneurosis before and after 4 weeks' treatment with food supplement "Supplement".

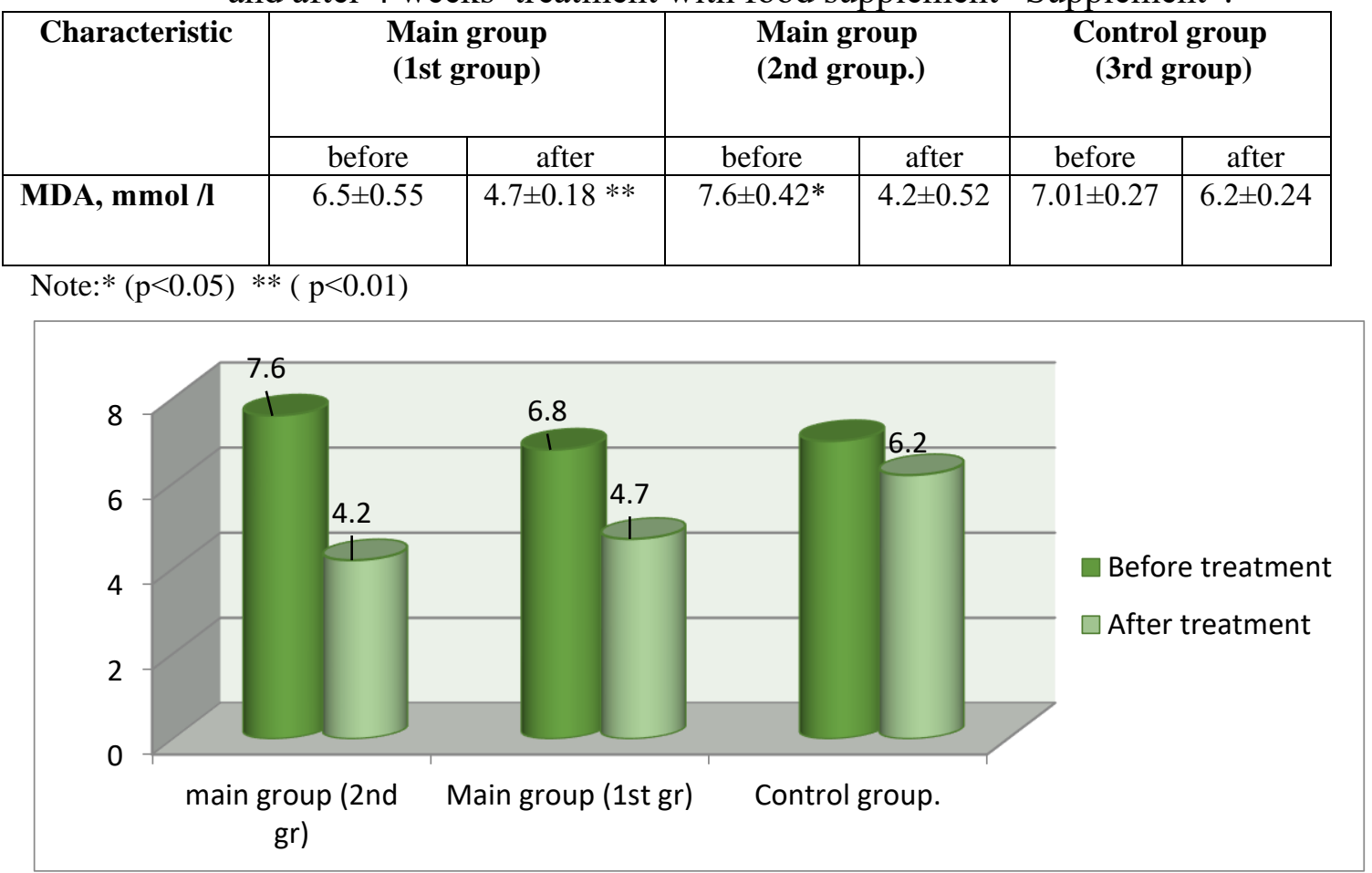

Figure 1. MDA level dynamics in patients with angioneurosis after 4 weeks' treatment.

Figure 1 shows dynamics in the 3 groups.The main substrate of LPO in liver microsomes is arachiodonic acid. Its microsome phospholipid decrease is followed by 
peroxidation decline. By analyzing the obtained data, we can suppose that food supplement "Supplement" has an inhibiting effect on arachiodonic acid synthesis.

This effect becomes even more prominent if we combine "Supplement" with "Gutta Viva". It probably explains LPO inhibitory process and antioxidant protection activation in the main groups compared with the control group.

Statistical analysis shows significant decline $(\mathrm{p}<0.05)$ of depression and anxiety level (table $6)$.

Table 6. Dynamics of psychosomatic disorders symptoms in the groups after 4-week treatment with food supplement "Supplement" in combination with food supplement "Gutta Viva".

\begin{tabular}{|l|l|l|l|l|}
\hline $\begin{array}{c}\text { Treatment } \\
\text { period }\end{array}$ & \multicolumn{1}{|c|}{ Groups } & $\begin{array}{c}\text { Beck scale } \\
\text { (points) }\end{array}$ & $\begin{array}{c}\text { Tsung scale } \\
\text { (points) }\end{array}$ & $\begin{array}{c}\text { Sheehan scale } \\
\text { (points) }\end{array}$ \\
\hline \multirow{2}{*}{$\begin{array}{c}\text { Before } \\
\text { treatment }\end{array}$} & Main group (1st gr.) & $28.0(27.0-29.0)$ & $63.0(62.0-64.0)$ & $37.0(34.5-39.0)$ \\
\cline { 2 - 5 } & Main group (2nd gr.) & $26.0(25.0-27.0)$ & $63.0(62.0-64.0)$ & $36.0(35.0-37.0)$ \\
\cline { 2 - 5 } & Control group (3rd gr.) & $28.0(27.0-29.0)$ & $62.0(61.0-63.0)$ & $37.0(34.0-39.0)$ \\
\hline \multirow{2}{*}{$\begin{array}{l}\text { After } \\
\text { treatment }\end{array}$} & Main group (1st gr.) & $20.0(20.0-21.0)$ & $45.0(44.0-46.0)$ & $19.0(18.0-19)$. \\
\cline { 2 - 5 } & Main group (2nd gr.) & $16.0(16.0-17.0)$ & $40.0(39.0-41.0)$ & $16.0(15.0-16.0)$ \\
\cline { 2 - 6 } & Control group (3rd gr.) & $28.0(27.0-29.0)$ & $60.0(59.0-61.0)$ & $27.0(26.0-28.0)$ \\
\hline
\end{tabular}

All the patients of the first two groups demonstrated psychic health improvement: anxiety average level by Beck Depression Inventory, Tsung and Sheehan scales showed significant decrease $(p<0.05)$. The third control group did not show any significant decrease (table 6).

Thus we can make a conclusion that food supplement "Supplement" intake improves patients' health conditions. We can speak of headache abatement, better memory retention and information retrieval, better attention and concentration, fewer emotional-volitional sphere disorders. Check-ups also showed lower blood pressure and positive EEG dynamics. Results in the first main group (only "Supplement" intake) were a bit worse than in the second group: $85 \%$ of participants of the first group observed improvement of their general health condition, $80 \%$ noted headache abatement and increased initiative, $85 \%$ showed better memory retention, $70 \%$ demonstrated fewer emotional-volitional sphere disorders and better muscle tone.

We can state that biologically active food supplement "Supplement" significantly improves cerebral blood flow, reduces blood viscosity, and protects cell membranes from damage.

Treatment with "Supplement" can improve brain metabolism which leads to better memory, concentration, increased initiative, weaker emotional-volitional disorders manifestation in patients suffering from angioneurosis.

Combination of food supplements "Supplement" and "Gutta Viva" (2nd main group) significantly influences disease manifestation. It improves antioxidant protection and stabilizes psycho- emotional state of patients with angioneurosis. The second main group also showed better results concerning clinical manifestations of angioneurosis: 100\% observed abated headache, the majority noted better health condition, memory retention, and information retrieval, $85 \%$ demonstrated positive EEG dynamics.

MDA level dynamics (LPO index) in the main groups was characterized by a significant inhibition of lipid peroxidation process, which proves reduced cell damage.

Psycho-emotional sphere study noted psychological condition improvement in all patients of the two main groups $(p<0,05)$. The best results were demonstrated by the second main group. The average level of anxiety by Sheehan scale was about 16 points. 


\section{Conclusions}

The obtained results allow for the following conclusions:

$\checkmark$ food supplement "Supplement" in combination with food supplement "Gutta Viva" facilitates cell membranes stabilization by reducing LPO processes, has significant antioxidation effect, improves patients' psycho-emotional condition and can be considered an effective treatment of patients with angioneurosis of moderate severity.

$\checkmark$ food supplement "Supplement" in combination with vascular drug Trental contributes to early relief of the main angioneurosis symptoms. If we combine it with food supplement "Gutta Viva" it significantly improves the general health condition, attention, concentration, initiative, normalizes the psycho- emotional sphere, reduces lipid peroxidation, has a pronounced antioxidant effect.

$\checkmark$ course treatment with in combination with Trental provides more pronounced therapeutic effect on disease progression, decreases LPO, improves psycho-emotional sphere.

$\checkmark$ course treatment with in combination with Trental improves brain metabolic processes, attention, memory, normalizes blood pressure and muscle tone.

$\checkmark$ the tested food supplement is characterized by good tolerability.

$\checkmark$ "supplement" can be recommended as an additional antioxidant source.

$\checkmark$ the developed product has the following competitive advantages:

$\checkmark$ cifrol-5 provides 24 hours' persistent antioxiadant protection.

$\checkmark$ scientifically valid food supplement formulation provides prolonged targeted effect;

$\checkmark$ pelletized form of the ingredients makes it possible to release tablet active substances in the certain order; $\checkmark$ single intake of the complex (one tablet a day) makes its use convenient and affordable;

$\checkmark$ physiological dosage of active substances prevents addiction and other side-effects.

Product "Supplement" was tested in production conditions at scientific-production association "Art-Life" enterprises in the city of Tomsk, certified in accordance with the requirements of the international standards series of the ISO 9000, 22000 and the GMP rules, which ensures quality consistency and competitiveness.

\section{References}

Avstrievskikh, A.N. Vekovtsev, A.A., Poznyakovsky, V.M. (2005). Healthy nutrition products: new technologies, quality assurance, efficacy. Siberian University Publishing House, Novosibirsk. pp. 416.

Chelnakova, N.G., Poznyakovsky, V.M. (2015). Contemporary people nutrition and health. Publishing House «Old Russians», Moscow. pp. 224.

Fenech, M., El-Sohemy, A., Cahill, L., Ferguson, L.R., French, T.A.C., Tai, E.S., Milner, J., Koh, W.P., Xie, L., Zucker, M. (2011). Nutrigenetics and nutrigenomics: Viewpoints on the current status and applications in nutrition research and practice. Journal of Nutrition. 4, 69-89.

Fulgoni, V.L., Keast, D.R., Bailey, R.L., Dwyer, J. (2011). Foods, fortificants, and supplements: Where do Americans get their nutrients. Journal of Nutrition. 141, 1847-1854.

Gemming, L., Jiang, Y., Swinburn, B., Utter, J., Ni Mhurchu, C. (2013). Under-reporting remains a key limitation of self-reported dietary intake: An analysis of the 2008/09 New Zealand Adult Nutrition survey. European Journal of Clinical Nutrition. 68(2), 259-264.

Gerasimenko, N.F., Poznyakovsky, V.M., Chelnakova, N.G. (2016). Healthy nutrition and its role in life quality assurance. Technologies of food and processing 
industry in agribusiness - healthy nutrition products. 4(12), 52-57.

Kondratiev, A.V., Shneider, N.A., Shulmin, A.V. (2015). Headache epidemiology. Modern science and education problems. № 6. pp. 23.

Krishnasree, V., Nethra, P.V., Dheeksha, J., Madumitha, M.S., Vidyaeswari, R., and Lakshya, P. (2018). A pilot study on assessing the sustainability of food safety and hygienic practices in street food handling system. Asian Journal Of Dairy And Food Research, 37(3): Online Published, 20-11-2018

Lafaille, F.G. (2012). Impaired intrinsic immunity to HSV-1 in human iPSC-derived TLR3-deficient CNS cells. Nature. 91(7426), 769-773.

Lebedeva, E.R., Kobzeva, N.R., Gilyov, D.V., Olesen, D. (2012) Health care organization analysis and management of patients with primary headaches. Ural Medical Journal, 6(120), 174-182.

Lund, N., Westergaard, M.L., Barloese, M. (2014). Epidemiology of concurrent headache and sleep problems in Denmark. Cephalalgia. 34(10), 833-845.

Manufacturing formula TC 027 / 2012 Product safety of some specialized food products, including dietary, medical and preventive nutrition.//docs.cntd.ru/document/90235282 3 (application date 20.09.2017).

Mirmiran, P. Bahadoran, Z. Azizi, F. (2014). Functional foods-based diet as a novel dietary approach for management of type 2 diabetes and its complications: A review. World Journal Diabetes. 5, 267-281.

Mozaffarian, D., Ludwig, D.S. (2010). Dietary guidelines in the 21 st century - A time for food. JAMA. 304, 681-682.

Osipova, V.V., Azimova Yu.E., Tabeeva, G.R. (2012). Headache diagnosis in Russia and former Soviet republics: problems and solutions. Annals of clinical and experimental neurology, 6(2), 16-22.

Poznyakovsky, V.M., Chugunova, A.A., Tamova, M.Y. (2017). Nutrition ingredients and biologically active food supplements. INFRA-M, Moscow. pp. 143.

Priya Sugandhi, G. (2018). Probiotics conventional benefits and cautions in intake - A review. Indian Journal of Agricultural Reviews, 39 (3): 251-254. DOI: 10.18805/ag.R-1749

Russia's health: Atlas / Edited by Bokeria L.A. $8^{\text {th }}$ edition. (2012). Bakoulev Centre for Cardiovascular Surgery, Russian Academy of Medical Sciences, Moscow. pp. 408.

Shukla, U.N., and Manju, L. M. (2018). Biofortification: Golden way to save life from micronutrient deficiency. Indian Journal of Agricultural Reviews, 39 (5), 202-209. DOI: 10.18805/ag.R-1807

Stovner, L., Hagen, K., Jensen, R., Katsarava, Z., Lipton, R., Scher, A., (2007). The global burden of 353 headache: a documentation of headache prevalence and disability worldwide. Cephalalgia. 27(3), 193-210.

Vekovtsev, A.A., Tokhiriyon, B., Chelnakov, A.A., Poznyakovsky, V.M. (2017). Evidence for Effectiveness and Functional Properties of Specialized Product in Clinical Trial. Human. Sport. Medicine. 17(3): 94-101. DOI: $10.14529 / \mathrm{hsm} 170310$.

Witte, K.K., Byrom, R. (2014). Micronutrients for chronic heart failure: End of the road or path to enlightenment. JACC Heart Fail. 2, 318-320. 